HERBERT KIMURA

https://orcid.org/0000-0001-6772-1863

UNIVERSIDADE DE BRASÍLIA

\title{
COVER LETTERS IN SUBMISSIONS FOR A BRAZILIAN SCIENTIFIC JOURNAL
}

https://doi.org/10.21452/procpc_01

Dissertação apresentada como parte dos requisitos para certificação no CSE Publication Certificate

Program

Brasília (DF)

2017 


\section{Cover Letters in Submissions for a Brazilian Scientific Journal}

\section{Herbert Kimura}

\section{Introduction}

Cover letters that accompany a manuscript submission to an academic journal are types of occluded genres (Swales, 1986) that are not directly visible in publications (Shaw, Kuteeva, \& Okamura, 2014). Many authors have discussed the fundamental role of cover letters (e.g., Azer, Dupras, \& Azer, 2014; Hafner, 2010; Yates, 2017), highlighting the characteristics and relevance of these documents in submissions to scientific journals.

Even though cover letters can be powerful tools to convince editors of the suitability of a paper in relation to the scope of the journal, authors often rush and overlook this important step in the submission process (Yates, 2017). In fact, Hafner (2010) indicates his surprise as an associate editor in realizing that authors often neglect to send a persuasive cover letter and do not describe why the study merits publication.

Azer, Dupras, and Azer (2014) even claim many authors do not know what to state in a message to a journal's editor. Though, as pointed out by John (2011), many editors affirm that they not seriously consider or even read the cover letters, authors should not risk carelessly preparing an introduction to their work.

Advances in technology, on the one hand, facilitate and universalize the submission process, but on the other hand, it may obscure the relevance of some documents valuable to editors. Authors sometimes become overwhelmed in the submission system by the need to gather and prepare mandatory material, such as thorough information about the authors (names, addresses, affiliations, grant numbers, ORCIDs, etc.) and the paper (title, abstract, manuscript files with or without authors' details, etc.) and, as a result, may pay little attention to communicating clearly with editors regarding why the journal should consider their work. 
In this article, we argue that by not investing the adequate effort in shaping a convincing cover letter, many authors miss an opportunity to position themselves and their papers and to improve the chances of not having their manuscript being desk rejected.

We analyzed a sample of 100 submissions to the Contemporary Management Journal (RAC; Revista de Administração Contemporânea), the flagship outlet of the National Association of Management Graduate Programs and Research (ANPAD; Associacao Nacional de Pos-graduacao e Pesquisa em Administracao), aiming to analyze whether and how authors structure cover letters.

The paper is structured as follows. In the next section, we briefly discuss arguments for thoughtfully preparing cover letters and present the main elements to be conveyed for editors. We then describe the methods and data of this study. Finally, we analyze the study's results. More specifically, we identify — in the case of this Brazilian scientific journal — that authors often do not give proper attention to preparing thoughtful cover letters.

\section{Theoretical Background}

Gump (2004) highlights the most evident objectives of cover letters are to identify the authors and to request consideration of manuscript for assessment and publication. As Yates (2017) argues, when papers were not submitted online, the cover letter was the very first material the editor would analyze; thus, the authors would have to be compelling regarding the paper's relevance.

Because many journals have migrated to digital submissions, basic information typically presented in cover letters - such as curriculum or author backgrounds, each author's contribution, a disclaimer of potential conflicts of interest, or an indication of preferred or non-preferred reviewers - can now be inserted in specific fields of the automatic system.

However, cover letters still have a relevant role, especially as opportunities for the submitter to reinforce the authors' credibility to ensure more serious consideration for 
publication and to start a productive rapport with the editorial team (Gump, 2004). More critically, Yates (2017) suggests authors may underestimate the influence of the cover letter and even miss out on their paper being sent for peer review due to poorly showing journal editors the contribution of the study to the field or to the readership.

Even though some editors do not really consider the cover letter during their decision (John, 2011), several studies suggest an essential role of this document (e.g., Azer et al., 2014; Gump, 2004; Hafner, 2010; Yates, 2017). In the context of conveying useful information for editors, Yates (2017) highlights four elements a cover letter should address: importance of the work, broad impacts of the research, the target audience, and whether an editor has encouraged the authors to submit the paper.

In addition to data regarding the paper's title and the authors' names, affiliations, and contact information, Azer et al. (2014) suggest that the cover letter should include a discussion about the problem and the rationale of the paper, emphasizing the research questions; a justification for the method used to investigate the problem; and a description of the key findings of the work, indicating the impact and relevance of the study to the specified field.

\section{Methods and Data}

To better understand cover letter characteristics, I analyzed a sample of the first 100 submissions to the RAC in 2016. The journal accepts manuscripts that explore diverse themes, research methods, and approaches within all fields of business administration and accounting. Theoretical essays, as well as quantitative and qualitative studies in Portuguese, Spanish, or English, are within the journal's scope.

The peer-reviewing process follows a double-blinded procedure, which is usual in the Brazilian scientific publishing community. The editor-in-chief and the associate editors are 
all volunteers and do not earn any financial or nonfinancial compensation for their work. There are no submission, processing, or publication fees for RAC.

The journal receives 500-600 submissions a year through Clarivate Analytics' ScholarOne Manuscripts system. Depending on the existence of special issues, RAC publishes 36-54 papers a year. Cover letters for the journal are not mandatory, and authors may therefore choose to send or not send any additional material —other than the manuscript without authorship information- to the editor.

This study is exploratory and descriptive and does not aim to make inferences regarding potential relationships among variables or value judgments regarding the quality of the cover letters. Despite its limited approach, the study illustrates the use of this traditional document in the agile environment of submission processes, which make use of information technology.

To gather the data, we logged into ScholarOne Manuscripts and accessed the papers' metadata about the journal. More specifically, we browsed the field related to cover letters, copying and pasting its content into a spreadsheet. We standardized some information to make analysis more manageable; for instance, deleting blank spaces, greetings, and curriculum vitae information in the cover letters.

\section{Discussion of Results}

Considering the sample of submissions to RAC, many authors miss the opportunity indicated by Gump (2004) to make the cover letter an asset to enhance the publication chances of the paper. From the sample of 100 submissions, $39 \%$ of the papers did not have any text in the cover letter field.

Though this item is optional for the journal, this percentage is surprisingly high, as, if properly used, cover letters could boost the perceived quality of a submission. Authors may be tired of filling out so much mandatory information during the submission process, 
however, and may feel relieved to not be required to write a cover letter; as John (2011) suggests, they are missing the opportunity to enhance the chances of their paper being reviewed.

From those 61 submissions that included some text in the cover letter field, 10 (16.4\%) replicated or made a few changes to the abstract. Though these letters depict repeated information described in the manuscript's file, they display some relevant elements, such as contributions of the paper, main themes, research questions, and the main results. It is important to highlight that when not copying the abstract, only 5 cover letters present this information.

Target audience, study impact, and methodology justification are rarely discussed in the cover letters submitted to RAC. Therefore, many cover letters suggest a general contribution of the paper to the field's literature without presenting essential or more detailed information regarding the merits of the research, lacking elements that Azer et al. (2014) and Yates (2017) consider relevant. Reflecting on the field of business administration scientific publishing in Brazil, 21 (34.4\%) submissions indicated the manuscript was a version of a study presented in a conference or a master thesis or doctoral dissertation.

Because the objective of the study is to describe the sample, I present some statistics. Cover letters averaged 217 words, with a median of 152 , a maximum of 716 , a minimum of 14, and a standard deviation of 170 words. As my goal was not to make value judgment regarding the quality of the cover letters or to analyze relationships between content and desk rejections, I did not study the relationship between the size and the quality of the cover letters or among other variables.

Some cover letters are unusual. For instance, one author shortly presents the story of his life, stating that his passion for that particular field of study began while attending preelementary school. Another author uses the cover letter only to ensure the editorial team that 
he would authorize the publication of the study, in case it is approved. Though these curious cover letters are exceptions, they suggest that even seasoned submitting authors overlook the importance of "selling" the paper to the editors.

Therefore, cover letters varied substantially not only in terms of length but in content.

Overall, few authors take the opportunity of the cover letter to communicate with the editorial team, conveying rich information that could be important in the decision-making process regarding the continuity of the manuscript through the editorial flow.

In this context, just a few cover letters explicitly contained a discussion about the contributions of the manuscript to theory and practice of management, bringing pertinent arguments and describing effective examples that justify the novelty of the study. Just two cover letters referenced past articles published by the journal.

\section{Final Considerations}

By analyzing a sample of manuscripts submitted to RAC, I seek to identify the main characteristics of cover letters written by RAC's authors. Regardless of whether the journal has a local scope — as most of the authors are from Brazil—I still find it interesting to study cover letter issues. To some extent, the study entails the discussion of a traditional tool, the cover letter, in the rapidly changing environment of scholarly publishing.

Results show that authors frequently neglect the important role of the cover letter, presenting shortened versions of the abstracts, giving standardized arguments, or even not submitting a message to help editors better identify the merits of the paper. 
References

Azer, S. A., Dupras, D. M., \& Azer, S. (2014). Writing for publication in medical education in high impact journals. European Review for Medical and Pharmacological Sciences, 18(19), 2966-1981.

Hafner, J. H. (2010). The art of the cover letter. ACS Nano, 4(5), 2487-2487. doi:10.1021/nn100907e

John, M. (2011). I really think you should publish this paper: The cover letter to the editor. HSR Proceedings in Intensive Care and Cardiovascular Anesthesia, 3(2), 137-113.

Shaw, P., Kuteeva, M., \& Okamura, A. (2014). Submission letters for academic publication: Disciplinary differences and promotional language. Journal of English for Academic Purposes, 14, 106-117. doi:10.1016/j.jeap.2014.02.002

Swales, J. M. (1996). Occluded genres in the academy: The case of the submission letter. In E. Ventola, \& A. Mauranen (Eds.), Academic writing: Intercultural and textual issues (pp. 45-58). Amsterdam, CT: John Benjamins.

Yates III, J. R. (2017). The cover letter. Journal of Proteome Research, 16(2), 367-367. doi:10.1021/acs.jproteome.6b01068 